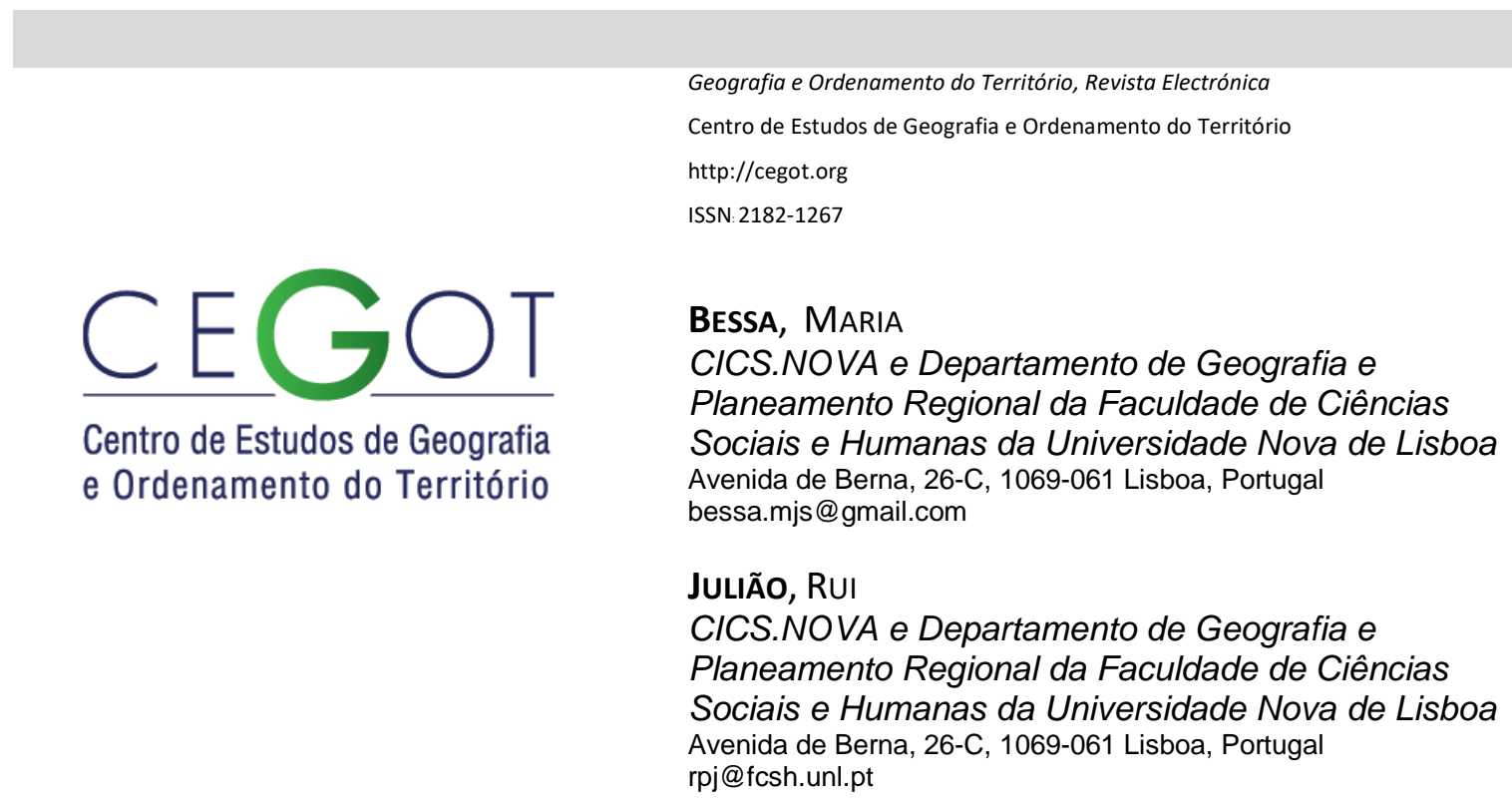

\title{
A informação geográfica e os Sistemas de Informação Geográfica como resposta aos desafios da gestão municipal: vantagens e desafios de uma implementação para o Inventário do Património Imóvel Municipal
}

\begin{abstract}
Geographic data and Geographic Information Systems as a response to municipal management challenges: advantages and challenges of an implementation on Municipal Property Inventory
\end{abstract}

Referência: Bessa, Maria; Julião, Rui (2016). A informação geográfica e os Sistemas de Informação Geográfica como resposta aos desafios da gestão municipal: vantagens e desafios de uma implementação para o Inventário do Património Imóvel Municipal. Revista de Geografia e Ordenamento do Território (GOT), n.o 10 (dezembro). Centro de Estudos de Geografia e Ordenamento do Território, p. 55-70, dx.doi.org/10.17127/got/2016.10.003

\section{RESUMO}

No cumprimento das suas atribuições e competências, os municípios necessitam de conhecer com rigor o seu património imóvel para poder responder de forma eficiente e eficaz às necessidades, expetativas e aspirações da comunidade. A existência de um cadastro e inventário georreferenciado de bens imóveis completo, rigoroso e atualizado permite ao Município conhecer a natureza, o estado, a afetação e o valor dos bens imóveis do domínio público e privado, determinar o seu melhor aproveitamento e promover a sua conservação e gestão integrada. O cadastro e inventário é uma obrigação legal, uma necessidade para a boa gestão e proteção dos bens patrimoniais e uma importante ferramenta para a definição de políticas públicas, com repercussões no ordenamento do território e nas finanças das autarquias locais. Importa avaliar o contributo dos SIG no 
desenvolvimento de uma solução que permita a gestão integrada e partilhada do património imóvel municipal e refletir sobre as vantagens e desafios da solução proposta.

Palavras-chave: Informação Geográfica, SIG, Gestão Municipal, Cadastro e Inventário, Património Imóvel Municipal.

\section{ABSTRACT}

In carrying out its duties and responsibilities, municipalities need to know with rigor its property assets to efficiently and effectively respond to the needs, expectations and community aspirations. The existence of a complete georeferenced real estate cadastre and inventory, rigorous and updated allows the municipality to know the nature, the state, the allocation and the value of real property in the public and private domain, determine its best use and promote conservation and integrated management. Cadastre and inventory are a legal obligation, a need for proper management and protection of assets and an important tool for the definition of public policies affecting spatial planning and finance of local authorities. It is important to assess the contribution of GIS to develop a solution that enables integrated and shared management of the municipal real property and consider on the advantages and challenges of the proposed solution.

Key-words: Geographic data, GIS, Municipal management, Cadastre and Inventory, Municipal Real Property.

\section{Introdução}

No quadro das suas atribuições e competências, os municípios necessitam de conhecer com rigor o seu património imóvel para poder responder de forma eficiente e eficaz às necessidades, expetativas e aspirações da comunidade (cidadãos/munícipes, agentes sociais e económicos e instituições públicas), mediante a adequada utilização dos mesmos à organização do território, promoção da habitação, construção e manutenção de infraestruturas, equipamentos, espaços verdes e outros espaços de utilização coletiva.

A existência de um Cadastro e Inventário do Património Imóvel Municipal (adiante designado por Inventário), completo, rigoroso e atualizado, permite ao Município conhecer, em qualquer momento, a natureza, estado, utilização, afetação e valor dos bens imóveis, indispensável para obter o seu melhor aproveitamento, velar pela sua conservação e promover a sua gestão integrada (Bessa, et. al., 2015). 
Para além de constituir uma imposição legal, o Inventário é uma necessidade para a boa gestão e proteção dos bens imóveis do património municipal e uma importante ferramenta para a definição e execução de políticas públicas pelo município, com repercussões no ordenamento do território e nas finanças das autarquias locais (Bessa, et. al., 2015).

Pretende-se com o presente artigo, analisar a importância da informação geográfica e dos SIG na gestão municipal, e mais concretamente na criação e manutenção do Inventário e no desenvolvimento de uma solução que constitua uma ferramenta eficaz e eficiente de controlo e gestão dos bens imóveis do património municipal.

\section{Novos desafios da Gestão Municipal}

Os municípios enfrentam, no âmbito das suas inúmeras atribuições e competências, um conjunto de desafios que deverão enquadrar as suas orientações estratégias para a gestão e ação, e suportar a definição e execução de políticas públicas inovadoras que promovam o desenvolvimento territorial sustentável, tendo como objetivo último a satisfação das necessidades, expetativas e aspirações da comunidade.

O novo paradigma da gestão pública municipal requer a adoção de critérios e princípios no sentido de uma gestão mais eficiente, visando a criteriosa escolha dos meios e recursos que permitam a obtenção do máximo rendimento na prossecução do interesse público municipal, e uma gestão eficaz, para alcançar os objetivos e as finalidades das políticas, dos programas, das ações e dos projetos.

A introdução de princípios de qualidade e inovação na gestão municipal passa pela adoção contínua de novos modelos organizativos e de soluções tecnológicas que permitam a racionalização dos serviços e a simplificação de procedimentos, conferindo celeridade aos processos de decisão, qualidade ao serviço prestado à comunidade e excelência ao desempenho pelos serviços municipais.

Este modelo de gestão pressupõe a adoção de uma cultura organizacional baseada na colaboração permanente entre as diversas unidades orgânicas, suportada numa adequada 
comunicação, orientada para os resultados, mediante a definição de objetivos, metas e indicadores de desempenho que avaliem o impacto das suas ações na comunidade, conferindo desta forma maior responsabilização.

A Governança surge como um novo desafio para a gestão municipal, baseada numa gestão participada e informada, mediante a criação de mecanismos de participação pública da comunidade na vida municipal.

Uma gestão municipal deve assentar também no rigor, na transparência e na responsabilização da gestão e decisão, assegurando os princípios de controlo internos que conferem aos serviços, e em especial aos dirigentes, a competência de desenvolver e manter os procedimentos que contribuam para garantir a condução ordenada e eficiente das atividades.

Deve garantir que o processo de planeamento municipal, enquanto instrumento administrativo de gestão municipal, incorpore os princípios da sustentabilidade, salvaguardando em simultâneo o desenvolvimento económico, coesão social e proteção ambiental.

A gestão municipal deve ainda contemplar critérios de rigor e sustentabilidade na gestão financeira e patrimonial, pelo reforço da capacidade financeira municipal, quer reduzindo as despesas de estrutura e funcionamento e os custos das atividades, ou aumentando as receitas apostando nos investimentos que incrementem a funcionalidade do património edificado, potenciem a sua utilização e em simultâneo promovam a sua valorização.

\section{A gestão do Património Imóvel Municipal}

Compete aos municípios a construção, conservação e reabilitação do edificado, dos equipamentos coletivos, do espaço público, de infraestruturas e de outros espaços de utilização coletiva, a gestão do trânsito e transportes, a salvaguarda dos interesses das populações no domínio do ambiente, energia, saneamento básico e da proteção civil, o 
ordenamento do território e urbanismo, contribuindo para a melhoria da qualidade de vida, para o desenvolvimento económico e a promoção da coesão social da comunidade.

A existência de um Inventário do Património Imóvel completo, rigoroso e atualizado, permite ao Município conhecer, em qualquer momento, a natureza, o estado, a utilização, a afetação e o valor dos seus bens imóveis, responder às necessidades desenvolvidas, e promover o incremento da economia, eficiência e eficácia das operações pelos serviços municipais ${ }^{1}$ no quadro da boa administração dos bens públicos e na salvaguarda do património municipal. Para além de ser uma imposição legal, a elaboração e manutenção do Inventário constitui-se também como uma necessidade para a boa gestão de ativos e proteção dos bens públicos partindo do princípio de que não é possível gerir bem, o que não se conhece (Bessa, et. al., 2015).

Acresce à perspetiva legal e de gestão, uma outra que considera o Inventário como um instrumento para a definição e execução de políticas públicas pelo município, de políticas públicas inovadoras, que contribuam para o desenvolvimento territorial, contemplando o desenvolvimento económico, a coesão social e a proteção ambiental, com repercussões no ordenamento do território e nas finanças das autarquias locais (Bessa, et. al., 2015).

\subsection{Apresentação da problemática: objeto e âmbito de aplicação}

O Inventário compreende todos os bens, direitos e obrigações constitutivos do mesmo ${ }^{2}$. Inclui:

- Bens do Domínio Privado;

- Bens de Domínio Público;

- Benfeitorias.

Tendo presente os benefícios do Inventário e considerando que toda a informação necessária para realização e manutenção do inventário dos bens imóveis se encontra nos

\footnotetext{
${ }^{1}$ Ponto 2.3 do Plano Oficial de Contabilidade das Autarquias Locais (POCAL), aprovado pelo Decreto-Lei n. 54A/99, de 22 de fevereiro, com as alterações que Ihe foram introduzidas pela Lei n.o 162/99, de 14 de setembro, Decreto-Lei n.ㅇ 315/2000, de 2 de dezembro e Decreto-Lei n.ㅇ 84- A/2002, de 5 de abril.

2 Ponto 2.8.1 do POCAL.
} 
diferentes serviços municipais, o que falta aos Municípios fazer, para realizar um inventário completo, rigoroso e atualizado?

As questões que se colocam são:

Q1. Como gerir um município, sem conhecer o seu património?

Q2. Como gerir o património municipal, sem conhecer os bens imóveis nas suas múltiplas dimensões, incluindo a sua localização geográfica?

Q3. Como gerir a informação de inventário sem dispor de uma solução que permita a sua gestão integrada e partilhada?

Q4. Tendo presente os benefícios do Inventário, por que razão, existem Municípios que não dispõem de um inventário completo, rigoroso e atualizado?

Q5. Tendo em conta que toda a informação necessária para realização e manutenção do inventário dos bens imóveis se encontra nos diferentes serviços municipais, que estratégia seguir para realizar um Inventário?

Q6. De que forma a utilização da informação geográfica e dos SIG poderão contribuir para o desenvolvimento de uma solução para a gestão de bens imóveis, coerente, credível e sustentável, criando mecanismos que promovam a organização e integração da informação dispersa pelos serviços municipais e ferramentas que facilitem a consulta e exploração e gestão da informação para os distintos fins e utilizadores?

Pretende-se desenvolver e apresentar um modelo interpretativo do problema proposto, nas suas diferentes perspetivas (jurídica, financeira, de planeamento e gestão urbanística, organizacional e regulamentar), e desta forma contribuir para a compreensão do problema, definição do objeto, conceitos e âmbito de aplicação, tendo em vista a identificação dos principais argumentos das opções técnicas a tomar.

\subsection{Perspetiva jurídica}

A Constituição da República Portuguesa ${ }^{3}$ prevê a existência de domínio público do Estado ${ }^{4}$ e indica em termos genéricos os elementos que o integram, referindo ainda que a Lei terá de

\footnotetext{
${ }^{3}$ Constituição da República Portuguesa - VII Revisão Constitucional (2005).

${ }^{4}$ Pertencem ao domínio público: a) As águas territoriais com os seus leitos e os fundos marinhos contíguos, bem como os lagos, lagoas e cursos de água navegáveis ou flutuáveis, com respetivos leitos; b) As camadas
} 
definir quais os bens que integram o domínio público das autarquias locais, o seu regime, condições de utilização e limites (cf. ponto 2. do Artigo 84.ํ). Refere ainda a Lei Fundamental que cabe à Assembleia da República, salvo autorização ao Governo, a exclusiva competência de legislar sobre a definição e regime dos bens do domínio público (cf. alínea v), do Artigo 165.ㅇ).

De acordo com a Lei $n .0$ 75/2013, de 12 de setembro5 , a elaboração e manutenção do inventário dos bens imóveis do património municipal é uma imposição legal, estando nele envolvido o Presidente da Câmara Municipal e os restantes órgãos executivos do município (Assembleia Municipal e Câmara Municipal).

A Lei $n .973 / 2013$, de 3 de setembro ${ }^{6}$, no quadro da autonomia financeira das autarquias locais, reforça as competências dos seus órgãos na gestão do património e finanças próprios (cf. Artigo 6.o), identificando o rendimento obtido na exploração dos bens, o produto de herança entre outras liberalidades e o produto da alienação de bens patrimoniais, como parte integrante das receitas municipais (cf. Artigo 14. ${ }^{\text {e) }}$ e por essa via parte integrante do Plano de Contas (cf. Artigo 74.ㅇ).

\subsection{Perspetiva financeira}

O Decreto-Lei n. 9 54-A $/ 99^{7}$, de 22 de fevereiro, que define o atual sistema contabilístico das autarquias locais (Plano Oficial de Contabilidade das Autarquias Locais - POCAL), refere no seu ponto 2.8.1 que "As autarquias locais elaboram e mantêm atualizado o inventário de todos os bens, direitos e obrigações constitutivos do seu património.", permitindo-Ihes a elaboração do balanço inicial e das demonstrações contabilísticas anuais exigidas no POCAL.

aéreas superiores ao território acima do limite reconhecido ao proprietário ou superficiário; c) Os jazigos minerais, as nascentes de águas mineromedicinais, as cavidades naturais subterrâneas existentes no subsolo, com exceção das rochas, terras comuns e outros materiais habitualmente usados na construção; d) As estradas; e) A As linhas férreas nacionais; f) Outros bens como tal classificados por lei. (cf. ponto 1. do Artigo 84.ㅇ).

${ }^{5}$ Estabelece o Regime Jurídico das Autarquias Locais.

${ }^{6}$ Lei das Finanças Locais

${ }^{7}$ Define o Plano Oficial de Contabilidade das Autarquias Locais. 
O Decreto-Lei n.․ $280 / 2007^{8}$, de 7 de agosto, introduz no regime do património imobiliário público, critérios de economia, eficiência, eficácia, racionalidade, equidade, concorrência, transparência, proteção e responsabilidade e controlo (cf. Artigos 3.ำ a 12.ํ), estabelecendo normas mais exigentes para a avaliação e gestão dos recursos públicos, no quadro dos princípios da boa administração e da proteção dos bens públicos. O decreto-lei obriga as autarquias locais a assegurar a organização e atualização periódica dos respetivos inventários dos bens de domínio públicos (cf. Artigo 117.ํ).

Este sistema contabilístico envolve um conjunto de tarefas e registos através do qual se processam as operações e acontecimentos como meio de manter atualizada a informação financeira do município, definindo o conteúdo mínimo obrigatório dos documentos de registo do inventário do património, bem como a respetiva explicitação, identificando a informação a incluir nas fichas respeitantes aos distintos bens (cf. ponto 2.8) a considerar no modelo de dados do solução a implementar.

\subsection{Perspetiva de planeamento e gestão urbanística}

A Lei n.ㅇ 31/2014, de 30 de maio ${ }^{9}$, determina que as autarquias locais devem, no âmbito da política pública de solos, de ordenamento do território e de urbanismo, garantir a existência de espaços públicos destinados a infraestruturas, equipamentos, espaços verdes e outros espaços de utilização coletiva, acautelando que todos tenham acesso aos mesmos em condições de igualdade (cf. Artigo 8.ํ), devendo esses mesmos espaços integrar o domínio público e privado de uma autarquia local (cf. Artigo 22.ํ).

O mesmo diploma obriga as autarquias locais a autonomizarem nos seus planos de atividade e orçamento, e nos documentos de prestação de contas, todos os bens imóveis integrantes do seu domínio público ou privado, e outros ativos patrimoniais (cf. Artigo 24.) e a proceder ao registo predial, inscrição matricial bem como a georreferenciação e a inscrição no cadastro predial, dos fatos que afetem direitos reais relativos a um determinado imóvel ou lhe imponham um ónus nos termos da lei (cf. Artigo 76.ํ).

\footnotetext{
${ }^{8}$ Estabelece o Regime Jurídico do Património Imobiliário Público.

${ }^{9}$ Estabelece as bases gerais da política pública de solos, de ordenamento do território e de urbanismo.
} 
Outro enquadramento que releva para esta problemática, é o que decorre dos diferentes regimes jurídicos que ao longo dos tempos regeram as operações de loteamento urbano, que consideraram sempre a obrigatoriedade de um particular efetuar cedências às câmaras municipais ${ }^{10}$.

O atual Regime Jurídico de Urbanização e Edificação (RJUE) estabelecido pelo Decreto-Lei 555/99, de 16 de dezembro, na atual redação dada pelo Decreto-Lei n.ำ 136/2014, de 9 de setembro $^{11}$, visa um maior equilíbrio entre a diminuição da intensidade do controlo prévio por parte da Câmara Municipal e o aumento da responsabilidade do particular e prevê a tramitação do processo através de plataforma eletrónica. O RJUE reforça o que foi determinado pelo anterior regime jurídico, estabelecendo que as parcelas que constituem áreas de cedências, de acordo com a lei e a licença ou comunicação prévia, devem integrar o domínio municipal com a emissão do Alvará, retirando a obrigatoriedade de registo na Conservatória do Registo Predial (cf. Artigo 44.ํ). O Alvará de Licença de Operação de Loteamento deve indicar as parcelas afetas ao domínios público e privado municipal e conter em anexo uma planta com a delimitação dessas parcelas (cf. Artigo 77.ㅇ).

A Figura 1 sistematiza os contributos mais importantes e estruturais de cada perspetiva apresentada relativamente aos objetivos desta investigação.

Como nota final, refira-se que a legislação que regulamenta a gestão do património municipal, se encontra dispersa. Acresce o facto de as normas de inventariação existentes (com exceção das que regulam o Cadastro Predial e do Regime Jurídico de Edificação e Urbanização) serem omissas quanto à obrigatoriedade desta incluir a georreferenciação (localização e delimitação geográfica) dos bens imóveis, tendo esta falha consequências ao nível da qualidade do inventário e da sua eficácia como ferramenta para o controle e gestão do património municipal.

\footnotetext{
${ }^{10}$ Decreto-Lei n. 46673, de 29 de novembro de 1965, Decreto-Lei n. 289/73, de 6 de junho, Decreto-Lei n.으 400/84, de 31 de dezembro e Decreto-Lei n. 0 448/91, de 29 de novembro.

${ }^{11}$ Corresponde à 13a alteração do RJUE.
} 
Constituição da República Portuguesa

Decreto-Lei n. ${ }^{\circ} 477 / 80$, de 15 de outubro - Inventário Geral do

Património do Estado

Decreto-Lei n ${ }^{\circ} 280 / 2007$, de 7 de agosto - RJ Património Imobiliário Público

Lei n. ${ }^{\circ} 75 / 2013$, de 12 de setembro - RJ das Autarquias Locais (AL)

Lei ${ }^{\circ} \cdot 73 / 2013$, de 3 de setembro Regime Financeiro das $A L$ e das entidades intermunicipais

Decreto-Lei n. ${ }^{\circ} 30 / 2015$, de 12 de fevereiro - regime de delegação de competências nas AL e entidades intermunicipais

\section{Perspetiva Financeira}

Decreto-Lei n. ${ }^{\circ}$ 54-A/99, de 22 de fevereiro - POCAL
- Identifica os bens que integram o dominio público e define o seu regime, condições e limites de utilização.

- Identifica os bens que integram o dominio público, o dominio privado e o património financeiro do Estado.

- Define critérios e normas mais exigentes para a avaliação e gestão no quadro dos principios da boa administração e da proteção dos bens públicos.

- Obriga as AL a assegurar a organização e a atualização periódica de elementos informativos relativos à natureza, ao valor e a utilização dos bens imóveis.

Define as competências dos orgãos das AL (Presidente da CM, CM e AM) na gestão do património municipal.

- Reforça as competências dos órgãos das AL na gestão do património e finanças próprios.

- Estabelece o regime de delegação de competências nas AL em diferentes domínios, prevendo a transferência de recursos financeiros e patrimoniais necessário e suficientes

Define o novo regime contabilistico das $\mathrm{AL}$, introduzindo a contabilidade patrimonial como um ativo do municipio, criando condições para a integração consistente da contabilidade orçamental, patrimonial e de custos.

- Obriga as AL a elaborarem e a manterem atualizado o inventário de todos os bens, direitos e obrigações constitutivos do seu património.

- Define o conteúdo minimo obrigatório dos documentos de registo do inventário do património.

\section{Perspetiva do Planeamento e Gestão Urbanistica}

$R J$ diversos - de operações de loteamento urbano, obras de urbanização e edificação Decreto-Lei n. ${ }^{\circ} 46673$, de 29 de novembro de 1965

Decreto-Lei n. ${ }^{\circ} 289 / 73$, de 6 de junho
Lein $031 / 2014$ de 30 de maio- Leide bases gerais da politica pública de solos, de ordenamento do território e de urbanismo
- Define o direito de usar e fruir o selo, no respeito pelos seus usos e utilizações previstos na lei e nos programas e planos territoriais e o direito de beneficiar e aceder em condições de igualdade aos bens do dominio público.

- Define o dever de utilizar de forma sustentável e racional o território e os recursos naturais, incluindo os bens do dominio público.

- As AL devem promover a politica pública de solos, de ordenamento do território e de urbanismo, e garantir a existência de espaços públicos.

- Os Proprietários devem ceder áreas para infraestruturas, equipamentos, espaços verdes e outros espaços de utilização coletiva.

- Obriga as AL a autonomizarem nos seus planos de atividade e orçamento e nos documentos de prestação de contas, todos os bens imóveis integrantes do seu dominio público ou privado.

- Obriga ao registo predial, inscrição matricial e georreferenciação os fatos que afetem direitos reais relativos a um determinado imóvel ou lhe imponhamum ónus nos termos da lei.

- O Requerente deve obrigatoriamente ceder para o domínio público da CM terrenos para a instalação de equipamentos urbanos.

- ... deve ceder para o dominio público da CM terrenos para a instalação dos equipamentos gerais para servir os loteamentos urbanos, tendo posteriormente fixado os parâmetros para as áreas minimas a ceder e a obrigatoriedade de apresentação de planta com a delimitação das parcelas.

Decreto-Lei n. ${ }^{\circ} 400 / 84$, de 31 de dezembro Decreto-Lei n. ${ }^{\circ} 48 / 91$, de 29 de novembro Decreto-Lei n. ${ }^{\circ 555 / 99}$, de 16 de dezembro
Definem com maior detalhe a tipologia de áreas a ceder a titulo obrigatório e gratuito, obrigam a pagamento de taxa municipal pelos encargos das infraestruturas urbanisticas ou ao pagamento em espécie com a cedência de lotes para o dominio privado, à emissão de Alvará com o registo das parcelas e respetivos usos e à apresentação de planta com a delimitação das parcelas .

Figura 1 - Contributos das diferentes perspetivas do enquadramento legal. 


\section{A Informação Geográfica e os SIG no Inventário e Gestão do Património Imóvel Municipal}

A Informação Geográfica, nas suas diferentes componentes, põe à disposição do político, do decisor, do técnico e do cidadão, os dados essenciais para a definição de políticas e adoção de medidas concretas de gestão de recursos e de atividades, nos mais diversos âmbitos de aplicação. Dadas as suas capacidades de integração de dados e análise espacial, os Sistemas de Informação Geográfica (SIG) são hoje considerados como uma ferramenta transversal de aplicação multidisciplinar, de suporte às atividades de gestão e de apoio à decisão e ação (Bessa, et. al., 2015).

Grande parte das atribuições dos municípios tem repercussões no território. Decorre daí a necessidade de ter permanentemente presente o diagnóstico da situação existente e o levantamento e descrição dos meios e recursos disponíveis, nomeadamente os bens imóveis do património municipal, para assim poder definir estratégias e ações concretas para a resolução dos problemas identificados, tendo como referência, critérios de eficiência e racionalização na gestão dos recursos públicos, no quadro da boa administração dos bens públicos e na salvaguarda do património municipal (Bessa, et. al., 2015).

A resolução do problema identificado passa pelo desenvolvimento de uma solução corporativa centralizada e coerente, credível e sustentável, suportada na utilização da informação geográfica e SIG.

O modelo de integração proposto deve basear-se no aproveitamento das soluções existentes em cada um dos serviços do município e no desenvolvimento de mecanismos que permitam a integração de dados e sistemas de informação, utilizando a informação geográfica e os SIG como elemento agregador.

O desenho conceptual da arquitetura funcional, quadro de referência para a arquitetura aplicacional, deve ainda prever a ligação a entidades externas para troca de informação.

O interface de exploração e gestão dos dados será disponibilizado em ambiente SIG, integrado na Infraestrutura de Dados Espaciais (IDE) do Município.

A solução a desenvolver deverá ter as seguintes especificações: 
- incorporar as regras e procedimentos de inventariação definidos em Regulamento.

- respeitar as responsabilidades funcionais, os circuitos de informação, de validação e controle de qualidade obrigatórios.

- promover a organização, o registo e a integração dos dados dispersos pelos serviços municipais.

- disponibilizar mecanismos que facilitem a consulta e exploração e gestão integrada da informação de Inventário numa perspetiva de aplicação multifuncional orientada para distintos fins e utilizadores internos.

- permitir a troca de informação com entidades externas, criando um novo ambiente de exploração e gestão da informação de inventário, com a necessária contextualização geográfica.

Uma solução que suporte os procedimentos de inventariação, assegurando a qualidade dos dados, a integração entre sistemas de informação, a articulação entre serviços municipais permitindo a gestão integrada e_partilhada dos bens do Património Imóvel Municipal.

\subsection{Vantagens e desafios da solução proposta}

São inúmeras as vantagens e os desafios colocados pela utilização da informação geográfica e dos SIG na realização do Inventário e na gestão do património imóvel municipal.

Constituem "vantagens":

i. A utilização da informação geográfica, por constituir o suporte físico para o Inventário, facilitando o processo de identificação dos bens imóveis. Todos os bens imóveis sujeitos a inventário têm uma componente espacial, a sua localização e correta delimitação geográfica torna a descrição, caracterização, classificação, valorização e registo dos referidos bens, mais completa e rigorosa.

ii. A georreferenciação dos bens imóveis, por contribuir para a compatibilização, verificação, validação e controlo de qualidade dos dados de inventário disponíveis nos serviços municipais, permitindo identificar e corrigir erros e omissões encontrados nos 
registos efetuados sendo igualmente uma preciosa ajuda na reconstituição do ciclo de vida de um bem imóvel, desde a sua criação/aquisição até ao seu abate.

iii. O desenvolvimento de uma solução suportada em tecnologia SIG, por facilitar a integração de dados com origem e formatos distintos ${ }^{12}$, e a integração com as aplicações de gestão de outras áreas de atividade ou negócio do Entreprise Resource Planning (ERP) do município ${ }^{13}$, permitindo a gestão integrada e partilhada dos bens do Património Imóvel Municipal.

iv. A disponibilização de uma solução webSIG integrada na IDE do município, por promover a disseminação do acesso à informação de inventário a outras áreas de intervenção municipal ${ }^{14}$, permitindo aos distintos utilizadores consultar a informação que se encontra nas aplicações existentes nos serviços municipais, utilizando como suporte de visualização e análise a informação geográfica.

Para além das vantagens expostas, importa agora elencar os desafios de implementação que a solução proposta apresenta.

Constituem "desafios técnicos/tecnológicos":

i. A definição de um modelo de dados flexível e multifuncional, que sirva os distintos propósitos da gestão municipal para além da gestão patrimonial, assegurando ainda a ligação do SIG com os diferentes sistemas de informação integrados no ERP do Município.

ii. O desenvolvimento uma solução transversal para o registo de dados e gestão da informação do inventário, que incorpore os circuitos de informação e procedimentos de verificação definidos no Regulamento, garantindo a completude, rigor e atualização do Inventário.

\footnotetext{
12 Informação vetorial, imagens, informação alfanumérica e informação documental, entre outros.

${ }^{13}$ Inventário e cadastro, processos de loteamento, obras e empreitadas, contabilidade analítica, habitação municipal, gestão documental, entre outras.

${ }^{14}$ Serviços responsáveis pelas infraestruturas e equipamentos, gestão do espaço público, limpeza urbana, proteção civil e segurança, entre outros.
} 
iii. O desenvolvimento de uma solução que promova a divulgação e facilite o acesso a informação e conhecimento relativo ao património imóvel municipal, potenciando a utilização desta informação e conhecimento noutras áreas de intervenção do município.

iv. O desenvolvimento de uma solução que garanta a integração de informação proveniente de entidades externas.

Fazem parte dos "desafios metodológicos/procedimentais":

i. A alteração da metodologia de inventariação, introduzindo a obrigatoriedade de utilização de informação geográfica no registo do bem imóvel e em todas as fases do seu ciclo de vida (desde a sua criação/aquisição até ao abate).

ii. A alteração de práticas "instituídas", suportada pela necessária alteração do Regulamento de Inventário e Cadastro do Património Municipal.

iii. A harmonização/simplificação de procedimentos: por tipo de bem; por proveniência/origem; por negócio jurídico, entre outros.

iv. A capacitação técnica dos serviços municipais, responsáveis pelo fornecimento dos dados e pela realização e manutenção do Inventário, na utilização da informação geográfica, por forma a assegurar a colaboração dos serviços municipais no projeto.

\section{Conclusão}

Os municípios enfrentam, no âmbito das suas inúmeras atribuições e competências, um conjunto de desafios que deverão enquadrar as suas orientações estratégias para a gestão e ação, e suportar a definição e execução de políticas públicas inovadoras que promovam o desenvolvimento territorial sustentável, tendo como objetivo último a satisfação das necessidades, expetativas e aspirações da comunidade (cidadãos/munícipes, agentes sociais ou económicos e instituições públicas). 
Os novos desafios da gestão municipal assentam nos princípios da eficiência, eficácia e racionalização dos recursos, na qualidade da prestação dos serviços, no rigor, transparência e responsabilização da gestão e decisão, através da adoção das melhores práticas, apostando no conhecimento, nas tecnologias de informação e comunicação e numa nova cultura organizacional.

A resolução dos problemas identificados no diagnóstico apresentado, passa pelo desenvolvimento de uma solução baseada na utilização da informação geográfica e dos SIG. Uma solução que disponha de mecanismos que promovam o registo e a integração da informação dispersa pelos serviços municipais e de ferramentas que facilitem a consulta, exploração e gestão integrada da informação de Inventário para os distintos fins e utilizadores internos, evitando assim os custos associados a erros de avaliação e gestão.

A utilização de informação geográfica e dos SIG como suporte informativo, técnico e metodológico aos procedimentos de inventariação, apresenta como vantagens assegurar a qualidade dos dados, a integração entre sistemas de informação, a articulação entre os serviços intervenientes (incluindo as entidades externas), a gestão de informação e de conhecimento (geográfico) e consequente a criação de valor e de vantagens competitivas nos Municípios.

Propõe-se então, o desenvolvimento de uma solução integrada, suportada em tecnologia SIG, que incorpore as regras e procedimentos de inventariação definidos em Regulamento, respeitando nomeadamente as responsabilidades funcionais, os circuitos de informação, de validação e controle de qualidade obrigatórios, que disponibilize mecanismos que facilitem o registo e consulta da informação pelos diferentes serviços intervenientes, que permita a troca de informação com entidades externas, criando um novo ambiente de exploração e gestão da informação de inventário, com a necessária contextualização geográfica.

Uma solução que facilite a criação do Inventário completo, rigoroso e atualizado, e permita a gestão integrada e partilhada dos bens imóveis do património municipal pelos diferentes serviços do Município de acordo com as suas atribuições e competências, promovendo a correta utilização e afetação dos mesmos na perspetiva da racionalização dos meios e recursos e na prossecução das políticas públicas de incidência territorial, apoiando assim o Município no cumprimento da sua Missão. 


\section{Referências bibliográficas}

BESSA, Maria João; JULIÃO, Rui Pedro (2015): A informação Geográfica e os Sistemas de Informação Geográfica na Gestão do Património Imóvel Municipal: vantagens e desafios de uma implementação. In Valores da Geografia. Atas do X Congresso da Geografia Portuguesa, Lisboa, 9 a 12 de setembro de 2015. Lisboa: Associação Portuguesa de Geógrafos. P.14-19. 978-989-99244-1-3.

\section{Legislação (pela ordem com que é referida no artigo):}

- Decreto-Lei n.o 54-A/99 de 22 de fevereiro. Diário da República N.o 44, 1.a série-A.

- Constituição da República Portuguesa - VII Revisão Constitucional (2005).

- Lei $n$. 9 75/2013 de 12 de setembro. Diário da República N. 176, 1. série.

- Lei $\mathrm{n}$. 0 73/2013 de 3 de setembro. Diário da República N. 169, 1. a série.

- Decreto-Lei n. 280/2007 de 7 de agosto. Diário da República N.o 151, 1. a série.

- Lei n. 31/2014 de 30 de maio. Diário da República N. 104, 1. série.

- Decreto-Lei n. $136 / 2014$ de 9 de setembro. Diário da República N.o 173, 1. a série.

- Decreto-Lei n. 477/80 de 15 de outubro. Diário da República N. 239, 1. série. 